\title{
Moradia adequada: um direito sobressalente como vital em tempos de Covid-19
}

\section{Adequate housing: a highlighted right as a vital in Covid-19 times}

Marilza Ferreira do Nascimento ${ }^{1}$

\begin{abstract}
Resumo: O presente artigo versa sobre a mora dos poderes públicos concernente à efetivação do direito fundamental à moradia para milhões de brasileiros e o agravamento das consequências da falta de habitação adequada em decorrência do surto pandêmico da Covid-19. Apresentam-se, inicialmente, alguns aspectos gerais interpretativos das cláusulas constitucionais garantidoras desse direito. A seguir, faz-se a comparação de dados sobre a Covid-19 e as condições habitacionais para demonstrar que o direito à moradia adequada se correlaciona diretamente com o direito à saúde e à vida. Conclui-se, ao final, pela inconstitucionalidade dos instrumentos de planejamento dos gastos públicos quando estes forem omissos em alocar recursos para se fazer fronte às prestações materiais, por intermédio das quais o direito à moradia adequada se realiza.
\end{abstract}

Palavras chaves: Moradia adequada, direito fundamental, mínimo vital, Covid-19.

\begin{abstract}
This article deals with the delay of public powers concerning the realization of the fundamental right to housing for millions of Brazilians social and the aggravation of the consequences of the lack of adequate housing due to the pandemic outbreak of Covid-19. Initially, some general interpretative aspects of the constitutional clauses guaranteeing this right are presented. Next, data on Covid-19 and housing conditions are compared to demonstrate that the right to adequate housing directly correlates with the right to health and life. It concludes, in the end, by the unconstitutionality of the planning instruments of public expenditures when they fail to allocate resources to face the material benefits through which the right to adequate housing is realized.
\end{abstract}

Key words: Adequate housing, fundamental right, vital minimum, Covid-19.

\footnotetext{
${ }^{1}$ Mestre em Direito Administrativo e ciência da Administração pela Universidade dos Estudos de Bolonha-Itália, doutoranda em Memória Linguagem e Sociedade inscrita no Programa de Doutorado em Memória Linguagem e Sociedade da Universidade Estadual do Sudoeste da Bahia (UESB), professora de Direito Administrativo da UESB.
} 


\section{Introdução}

A necessidade inerente ao ser humano de habitar em lugar seguro e salubre onde possa conviver e se desenvolver remonta ao abandono do nomadismo. Desde então, possuir moradia se tornou condição básica, indispensável à preservação da integridade física e da saúde corporal e mental. Os processos civilizatórios e políticos atravessados pelas sociedades modernas, transformaram essa necessidade em direito social, consagrado em normas de direito internacional e em regramentos insertos no ordenamento jurídico de vários países.

De acordo com o art. 25 da Declaração Universal dos Direitos Humanos (DUDH) de 1948, "Todo o homem tem direito a um padrão de vida capaz de assegurar a si e a sua família saúde e bem-estar, inclusive alimentação, vestuário, habitação (...)". Por sua vez, o art. 11 do Pacto Internacional dos Direitos Econômicos e Sociais (PIDESC) obrigou os Estados Partes a proporcionarem o fornecimento de moradia adequada a todas as pessoas.

No que se refere especificamente ao Brasil, além de sua vinculação às mencionadas normas internacionais, o direito à moradia se consubstancia em direito social fundamental previsto no artigo $6^{\circ}$ da Constituição Federal de 1988 (Emenda Constitucional n ${ }^{\circ} 26$ de 31.01.2000). No entanto, verifica-se persistente discrepância entre a previsão constitucional e as situações fáticas notoriamente verificadas no território nacional.

Embora seja uma obra de ficção, o romance naturalista O Cortiço - publicado em 1890 - desvela de forma contundente a condição subumana a que brasileiros eram submetidos, mesmo na capital da República. Mais de um século depois, agora numa abordagem científica, Nascimento e Braga (2009), Vasconcelos e Cândido Jr (1996) e Russo (2015) demonstram que o avanço do déficit habitacional associado à inadequação e à insuficiência das políticas governativas para equacioná-lo são, ainda, infelizmente, realidades presentes, principalmente, em grandes espaços urbanos. Em que pese em 2009 o "Programa Minha Casa, Minha Vida" ter se revelado como diferencial nas históricas políticas habitacionais excludentes dos mais pobres, a insuficiência do seu alcance, antes notória, destacou-se com o advento da pandemia da doença Covid-19.

Por recomendar como principal forma de prevenção o afastamento social, segundo a Organização Mundial da Saúde (OMS), a pandemia da Covid-19 reafirmou a essencialidade do direito à moradia e potencializou para os estados a urgência em rendê-lo efetivo. Diante da recomendação expedida pela OMS, corroborada por epidemiologistas, infectologistas e governantes em meio a esse surto viral, no sentido de que as pessoas se afastassem das atividades presenciais e permanecessem em suas casas, foram explicitados diversos problemas relacionados 
à falta/inadequação de moradia. Surgiram-se, assim, algumas indagações importantes, como por exemplo: como se isolar em casa quando não se tem casa? Como se manter isolado, se a realidade diária é viver em barracos amontoados em favelas? Como suportar o convívio familiar em um espaço minúsculo? Como atender às orientações de higiene, se não se tem instalações sanitárias nem água potável em casa?

É importante registrar que até o surto pandêmico da Covid-19, os meios de comunicação mostraram exaustivamente os problemas relacionados à falta de moradia ou de moradia adequada, tais como: a) famílias vitimadas por incêndios, desabamentos e alagamentos de habitações construídas de maneira precária, em locais impróprios (aterros sanitários, encostas, baixadas) e sem observância de normas técnicas de segurança; b) assassinatos e espancamentos de moradores de rua; c) inúmeras famílias sem-teto envolvidas em ocupações de prédios e terrenos urbanos vitimadas por atos de despejos, não expressavam para inteira sociedade a dimensão mais gravosa da histórica indiferença dos poderes públicos relativa à efetivação do direito social à moradia, mesmo sendo este implícito no ordenamento jurídico brasileiro desde a Constituição de 1934 e expresso na Constituição de 1988.

Segundo os fatos noticiados pela mídia, os habitantes das favelas são os membros sociais mais expostos à contaminação e mais fatalmente vitimados pela Covid-19. Dessa forma, mais do que nunca, se explicita o entrelaçamento entre o direito à moradia e o direito à saúde e à vida. Diante dessa circunstância, este trabalho se propõe a discutir o direito fundamental social à moradia adequada, como direito fundamental imediatamente exigível.

Além dessa introdução, Seção 1, este artigo se compõe de mais três partes. Na seção 2, em breves linhas, à luz dos dispositivos constitucionais pertinentes, se falará sobre a eficácia do direito à moradia enquanto norma jurídica diretamente aplicável aos casos concretos. Na Seção 3, tratar-se-á sobre a exigibilidade imediata do direito à moradia e sobre o dever que têm os poderes públicos de render-lhe efetivo. Na Seção 4, tomando-se como base a vulnerabilidade sanitária das pessoas desprovidas de moradia adequada em face da Covid-19, se demonstrará a inconstitucionalidade por omissão dos orçamentos públicos que não aloquem os recursos necessários para se efetivar o direito à moradia adequada. Para tal, serão analisados textos doutrinários e a constituição brasileira. Por último, se apresentarão considerações finais.

\section{A aplicabilidade imediata das normas de direitos fundamentais e o direito à moradia}

A Constituição brasileira, no parágrafo $1^{\circ}$ do art. $5^{\circ}$, estatui que "As normas definidoras de direitos e garantias fundamentais têm aplicação imediata". Como mencionado, o direito à moradia no Brasil compõe o rol dos direitos sociais fundamentais previstos no art. $6^{\circ} \mathrm{da}$ 
Constituição. Os direitos sociais, segundo Moraes (2002, p. 43), “caracterizam-se como verdadeiras liberdades positivas, de observância obrigatória em um Estado Social de Direito, tendo por finalidade a melhoria das condições de vida aos hipossuficientes, visando à concretização da igualdade social, que configura um dos fundamentos de nosso Estado Democrático, conforme preleciona o art. $1^{\circ}$, IV". A conformação jurídica dispensada aos direitos sociais pelos constituintes de 1988 denotam que eles não eram alheios a essa compreensão.

Como afirmado em doutrina, a exemplo de Branco (2009, pp 285-287), o significado essencial da cláusula em questão é que as normas definidoras dos direitos fundamentais possuem natureza preceptiva e que os direitos fundamentais encontram os seus fundamentos diretamente na Constituição. Sobre a aplicabilidade imediata do dispositivo constitucional que garante o direito à moradia, observa-se que o constituinte não fez distinção entre normas de direitos fundamentais de garantia e normas de direitos fundamentais sociais. Logo, essa regra vale indistintamente para ambas as categorias. Sobre esse ponto, Sarlet é categórico ao afirmar que "o postulado da aplicabilidade imediata (art. $5^{\circ}, \S 1^{\circ}$ da CF) engloba todos os direitos fundamentais, inclusive os direitos sociais a prestações de cunho inequivocamente "programático"' (2007, p. 392).

Daí decorre que a maneira como esses direitos estão positivados no texto constitucional determina o quanto de eficácia podem desencadear, mas não a aplicabilidade em si, visto que, "por menor que seja sua densidade normativa no nível da Constituição", os direitos fundamentais à prestação "estão sempre aptos a gerar um mínimo de efeitos jurídicos, sendo, na medida desta aptidão, diretamente aplicáveis" (SARLET, 2007, 297). Este entendimento se coaduna com o postulado da inexistência de norma constitucional desprovida de eficácia (ALEXY, 2008; CANOTILHO, 2002; SILVA, 2000).

$\mathrm{Na}$ linha do quanto exposto até aqui, a plena eficácia das normas de direitos fundamentais sociais depende da atividade mediadora dos Poderes Legislativo e Executivo, aos quais compete, segundo Canotilho, promover as transformações econômicas e sociais necessárias para a efetivação desses direitos. Dessa forma, no que diz respeito à garantia do mínimo existencial, têm aplicabilidade imediata com fundamento diretamente na Constituição, como resultante "do dever indeclinável dos poderes públicos de garantir a dignidade da pessoa humana", independentemente da densificação jurídico-constitucional dos direitos sociais. É nessa perspectiva que doravante será tratado o direito à moradia. 


\section{Exigibilidade do direito à moradia à luz da constituição brasileira}

Entende-se que a moradia figurava como direito social implícito nas constituições brasileiras desde 1934. Se alguma dúvida restasse, essa foi sanada pela Constituição de 1988, cuja opção pela consagração do Brasil como Estado Democrático de Direito, portanto garantidor dos direitos fundamentais na sua acepção positiva (SILVA, 2000), vem expressa no caput do art. $1^{\circ}$, e reafirmada em vários outros dispositivos, quando trata dos valores, objetivos e direitos fundamentais, da ordem econômica e da ordem social.

Portanto, o direito à moradia antes de expressamente compor o rol dos direitos sociais fundamentais resultava implícito em vários dispositivos constitucionais, posto que decorre do princípio da dignidade humana, do direito à vida, à saúde, à privacidade, à inviolabilidade do domicílio, ao sigilo da correspondência, à educação e de vários outros direitos fundamentais assegurados expressamente no texto original da Constituição de 1988.

Como observou Souza (2004), todos esses direitos pressupõem a garantia do direito à moradia, sem o qual aqueles não se realizam.

Constata-se com Alexy (2008) que os mandamentos constitucionais não se apresentam apenas nas regras textuais, como também implicitamente, por meio de normas constitucionais atribuídas, cujo reconhecimento se faz indispensável à materialização das normas expressas. Neste sentido, Ingor Sarlet também é categórico ao dizer:

De qualquer modo tendo em conta de que a moradia (...) guarda conexão direta com as necessidades vitais da pessoa humana, e, por conseguinte, também com as condições materiais básicas para uma vida com dignidade, já se poderia, a exemplo do que fez o Conselho Constitucional da França, partir da premissa de que nossa ordem constitucional vigente já consagrava o direito à moradia. (SARLET, 2007, p. 329)

Essa referência à garantia implícita do direito à moradia nas constituições brasileiras, especialmente no texto original de 1988, se faz importante apenas para se explicitar a mora dos poderes públicos brasileiros na efetivação do direito à moradia, em afronta aos mandamentos constitucionais. A Emenda Constitucional n ${ }^{\circ}$ 26, de 31.01.2000, inseriu o direito à moradia no catálogo dos direitos fundamentais sociais. Desde então, a exigibilidade desses direitos se apresenta inequívoca no art. $6^{\circ}$, combinado com o $\int 1^{\circ}$ do art. $5^{\circ}$ da Constituição de 1988.

Há de se observar que após a promulgação da Constituição de 1988, verificou-se “um amplo movimento de organização e mobilização social em torno da política habitacional, na luta pelo processo de redemocratização da sociedade e planejamento para politicas sociais de habitação" (Silva; Gomes, 2016, p.139). Nessa esteira, o Congresso Nacional aprovou a Lei 10.257, de 10.06.2001 (Estatuto da 
Cidade), que vinculou o cumprimento das funções sociais das cidades e da propriedade urbana à garantia do direito à moradia. ${ }^{2}$

Ocorre que à semelhança dos demais direitos sociais prestacionais, o direito fundamental à moradia não se autorrealiza; sua plena eficácia carece de ações governamentais, por parte do Poder Público, orientadas e volvidas na formulação e na implementação de políticas sociais e econômicas condizentes com as regras, normas e valores constitucionais. Em face do consenso jurídico universal sobre a supremacia das normas constitucionais e sua força vinculante sobre todos os poderes, instituições, órgãos e agentes públicos (CANOTILHO, 2002; BARROSO, 2019), há de se admitir que o acesso à moradia adequada, compreendida no sentido de Prado e Pelin $(1993)^{3}$, constitui-se direito fundamental imediatamente exigível, devendo os poderes públicos competentes prontamente alocarem os recursos e criarem os meios para sua concreta fruição, sob pena de serem juridicamente responsabilizados por suas omissões.

Tendo-se demonstrado que a exigibilidade imediata do direito à moradia se faz inequívoca no texto constitucional, no tópico seguinte discutiremos a inconstitucionalidade por omissão dos orçamentos públicos que não aloquem, segundo parâmetros de razoabilidade e proporcionalidade, os recursos necessários para a efetivação desse direito, relacionando-o ao direito à saúde e o direito à vida.

\section{O surto pandêmico da Covid-19 e a reafirmação da exigibilidade imediata do direito à moradia adequada enquanto necessidade vital}

Até o surto da Covid-19, embora se correlacionasse o direito à moradia ao direito à saúde e à vida, parecia que a natureza vital desse direito restava obscurecida aos poderes públicos. No entanto, durante essa pandemia desvelou-se para a sociedade em geral as gravosas consequências da histórica omissão estatal em proporcionar moradia adequada a todos.

Observa-se que são vários os fatores concorrentes para a maior ou menor propagação da coronavírus SARS-CoV-2 no território nacional e não se pode olvidar que as condições habitacionais se revelam dentre eles, como um dos elementos mais importantes. Os dados fornecidos pelo Ministério da Saúde (MS), em 27.06.2020, indicam que a maior parte dos casos de contaminação e de vítimas fatais da Covid-19 se encontram nas regiões Nordeste, Norte

\footnotetext{
${ }^{2} \mathrm{O}$ Estatuto da Cidade foi, em muitos aspectos, considerado um avanço importante concernente ao direito à cidade, tendo, no âmbito municipal, propulsionado a participação popular nas discussões que antecederam as aprovações dos planos diretores urbanos. Sobre este tema, vide Carvalho e Rodrigues (2016).

${ }^{3}$ Segundo Prado e Pelin, "Moradias adequadas são habitações nas quais reside uma única família, que sejam servidas por redes de água e esgoto, e que não sejam nem habitações improvisadas nem habitações precárias, independentemente de serem alugadas, próprias ou cedidas gratuitamente" (PRADO; PELIN (1993) apud VASCONCELLOS; CÂNDIDO JR. (1996, p.8).
} 
e Sudeste do país. E, segundo dados estimativos de 2019, fornecidos pelo Instituto Brasileiro de Geografia e Estatística (IBGE), também são nessas regiões onde se verificam a maior concentração de aglomerações subnormais. A relação entre a contaminação pela covid-19 e habitações em aglomerações subnormais se confirma de forma inversa nas regiões sul e centrooeste, onde se verificam as menores incidências desses fatores.

As razões para isso são diversas e não constituem objeto desse trabalho, mas é possível se afirmar que nas moradias em que famílias vivem aglomeradas em prédios rústicos, com inadequadas condições de habitabilidade, é pouco provável que se concretizem o isolamento social e o distanciamento, evidências de um grave problema no contexto da pandemia, dado que essas são as recomendações das autoridades sanitárias para evitar a propagação da doença e consequente colapso do sistema público de saúde. Certo é, que a trágica experiência dessa pandemia explicita o que há muito vem sendo dito por doutrinadores brasileiros e olvidado pelos poderes públicos: o direito à moradia possui caráter existencial, é expressão do próprio direito à vida (SARLET, 2008, p. 329), e, como tal, diretamente exigível.

Não há dados estatísticos oficiais atualizados sobre as condições de moradia no Brasil. O último Censo Demográfico realizado pelo Instituto Brasileiro de Geografia e Estatística (IBGE) data-se de 2010. Entretanto, mediante seus dados estimativos, tem-se que milhares de famílias brasileiras vivem em moradias inadequadas, encrustadas em aglomerados subnormais. Segundo sua projeção para o censo demográfico de 2020 (adiado para 2021), no Brasil existem aproximadamente 5.127.747,00 de domicílios situados nessas aglomerações. Consoante sua definição, in verbis:

Os aglomerados subnormais são formas de ocupação irregular em áreas urbanas, para fins de habitação, de terrenos de propriedade alheia (públicos ou privados). Em geral, são caracterizados por um padrão urbanístico irregular, carência de serviços públicos essenciais e localização em áreas com restrição à ocupação. Em alguns Municípios são conhecidos como favelas, comunidades, grotas, palafitas, invasões, ressacas e outras nomenclaturas (IBGE, 2020).

Sabe-se que desde 1964 os governos vêm adotando políticas públicas com vistas a solucionar/minorar o problema do déficit habitacional por meio do Sistema Financeiro de Habitação, inicialmente gerido pelo Banco Nacional de Habitação (BNH) e administrado pela Caixa Econômica Federal a partir de $1986 .{ }^{4}$ Contudo, os dados acima demonstram que as políticas governamentais consubstanciadas na abertura de crédito para financiamento da casa própria e aquisição de materiais de construção para aqueles que demonstrem capacidade de

\footnotetext{
${ }^{4} \mathrm{O}$ BNH foi extinto em 1986 (Decreto-Lei 2.251) e a Caixa Econômica Federal assumiu o seu patrimônio e suas
} atribuições. 
pagamento não se constituem em meio idôneo para solucionar o problema da falta de moradia para milhões de brasileiros. Assim, para o extrato social mais pobre, conforme Russo (2015), as políticas habitacionais precisam ser custeadas com recursos públicos e essas devem se inserir em um planejamento estatal estratégico de curto, médio e longo prazo. ${ }^{5}$

Ressalta-se que a realização do direito à moradia, assim como dos demais direitos sociais fundamentais, não constitui parte de um programa de governo que possa ser adotado ou descartado de acordo com as convicções políticas, econômicas e sensibilidade social dos governantes que se alternam no poder; essa compõe um direito universalmente assegurado e integra o programa de Estado delineado no texto constitucional de 1988. Desse modo, impõe-se aos entes federativos incluir nos seus planejamentos financeiros e orçamentos anuais a alocação de recursos para garantir moradia adequada para a população que não dispõe de meios próprios para obtê-la, sob pena de incorrerem em atos de violação constitucional por omissão, a qual pode e deve ser corrigida pelo Poder Judiciário.

À semelhança do direito à saúde, o acesso à moradia adequada compõe a categoria dos direitos mínimos existenciais, à medida que, além de indispensável à própria preservação da vida e da saúde física e psicológica dos indivíduos, condiciona a realização de outros direitos individuais e sociais. Portanto, merece a mesma proteção jurisdicional.

Os argumentos em derredor do grau de positivação dos direitos sociais, da inexistência de dotação orçamentária, da reserva do possível, do princípio da separação dos poderes e da dificuldade de se mensurar o mínimo necessário à garantia da dignidade humana, todos adotados para negar efetividade aos direitos sociais, pelo menos na sua dimensão mínima, não mais se sustentam em face da explícita correlação direta do direito à moradia com o próprio direito à vida.

Por certo, o mínimo existencial tem conteúdo jurídico aberto e torna impossível uma definição de forma objetiva. No entanto, é com os dados objetivos da realidade social e econômica brasileira que compete aos julgadores determinar as situações subjetivas diante das quais o direito é exigível e os parâmetros dentro dos quais a reserva do possível poderá ser legitimamente invocada.

É de se clarear que o mínimo existencial que justifica uma postura mais incisiva do Judiciário no controle das decisões de governo no Brasil - pelo menos até que todos tenham acesso às condições básicas de sobrevivência, como alimentação, moradia, educação fundamental

\footnotetext{
${ }^{5}$ Nesse sentido, a concepção do Programa Minha Casa, Minha Vida consistiu em um programa inicial, que precisaria ser mantido, melhorado e ampliado. Sobre dados e avaliações do Programa, vide dentre outros, Amoré; Shimbo; Cruz (2015).
} 
e profissionalizante, assistência social e aos tratamentos de saúde possíveis de serem razoavelmente exigidos - deve ser interpretado no sentido literal da expressão, entendido como direito às prestações sociais apenas na medida do necessário para a liberação dos cidadãos das necessidades que aviltam sua condição humana e inviabilizam o exercício dos direitos individuais, de acordo com padrões compatíveis com as condições concretas do país.

Vale observar que a reserva do possível, invocada em várias decisões do Supremo Tribunal Federal (STF), não pode ser compreendida como simples inexistência de dotação orçamentária. A adequada compreensão do seu conteúdo se remete para a falta de possibilidades materiais concretas de realização do direito, sem o sacrifício de outros feitos públicos concretizadores de direitos igualmente relevantes, ficando a falta de possibilidade jurídica, ou seja, a ausência de previsão orçamentária, relativizada ante a possibilidade de correção do orçamento, tudo baseado nos inarredáveis critérios da proporcionalidade e da razoabilidade.

Bem lembrou Krell (1999, p. 247) que “A interpretação dos direitos sociais não é uma questão de 'lógica jurídica', mas de consciência social de um sistema jurídico como um todo". O movimento em direção à maior efetividade dos direitos sociais, ressalta Canotilho, depende de muitos fatores além do desenvolvimento e capacidade econômica do Estado. Dentre esses fatores o autor cita o "clima espiritual da sociedade", o "nível de ensino" e as "convenções sociais, éticas, filosóficas ou religiosas". Os valores, os fins públicos e os comportamentos contemplados nos princípios e regras da Lei Maior passam a condicionar a validade e o sentido de todas as normas do direito infraconstitucional". Ressalta-se que nesse entendimento se incluem as normas orçamentárias e a execução dos orçamentos públicos.

Assim, não se pode olvidar que a efetividade dos direitos sociais no Brasil reclama mudança substancial na compreensão da discricionariedade das decisões políticas provenientes do Legislativo ou do Executivo, de modo a alargar o controle judicial sobre as definições das políticas públicas e os instrumentos de planejamento dos gastos estatais. Isso porque, como há muito se observa, o problema da pouca efetividade dos direitos fundamentais sociais "parece estar na formulação, implementação e manutenção das respectivas políticas públicas e na composição dos gastos nos orçamentos da União, dos estados e dos municípios" (KRELL, 1999, p. 242).

Do mesmo modo que as demais atividades públicas, "Um orçamento público, quando não atende aos preceitos da Constituição, pode e deve ser corrigido mediante alteração do orçamento consecutivo, logicamente com a devida cautela" (KRELL, p.253/254). Entende-se que, mesmo quando em andamento, o orçamento poderá ser corrigido por determinação judicial a fim de se eliminar possíveis distorções, com vistas a imprimir maior efetividade aos direitos 
sociais e garantir a todos o mínimo vital concernente aos direitos fundamentais em geral e, em especial, ao direito à moradia.

Os direitos prestacionais exigem grandes investimentos públicos, os quais devem estar inseridos nos instrumentos de planejamento das despesas públicas. Esses, por suas vezes, devem estrita consonância com as regras e escolhas programáticas da Constituição, as quais são múltiplas e exigem indistintamente atenção dos poderes públicos. Nesse sentido, invoca-se Canotilho (2002) para dizer que cabe aos Tribunais juridicamente controlarem se há nas escolhas discricionárias públicas razoabilidade fundada no princípio da igualdade.

Diante da necessidade premente de se instituir um programa de habitação popular para as camadas carentes de moradia adequada, faz-se oportuno resgatar um antigo Acórdão do STF, no qual o Ministro Marco Aurélio de Mello afirma: “A INTERPRETAÇÃO DA NORMA PROGRAMÁtICA NÃO PODE TRANSFORMÁ-LA EM PROMESSA CONSTITUCIONAL INCONSEQUENTE. Ante a omissão legislativa e administrativa em atuar a Constituição, cabe aos juízes promoverem as devidas correções" (Ministro CELSO DE MELLO Relator. Decisão publicada no DJe de 5.8.2013. INOVAÇÕES LEGISLATIVAS. Lei $\mathrm{n}^{\mathrm{o}}$ 12.862, de 17.9.2013 - Altera a Lei no 11.445/2007. Publicado no DOU em 18.9.2013, Seção 1, p. 1). Nesse Acórdão, ele cita o Min. Carlos Fux, para quem o princípio da separação de poderes, concebido para garantir os direitos individuais, não se presta ao entrave da realização dos direitos fundamentais sociais e não significa que o "Judiciário deva permanecer indiferente ante à omissão governativa em adotar as políticas públicas necessárias à realização desses direitos". Assim, estão postos todos os elementos jurídicos normativos e interpretativos necessários à realização do direito à moradia. Cabe à sociedade exigir dos governantes as ações implementadoras e do judiciário a correção de suas omissões.

\section{Conclusão}

O Direito à Moradia encontra-se consolidado na Ordem Constitucional como Direito Social Fundamental e visa preservar o bem maior que é a vida e o princípio da dignidade da pessoa humana. No entanto, a realidade habitacional de milhares de pessoas que vivem em aglomerações subnormais demonstra a ausência e a insuficiência das políticas governamentais direcionadas a realização do direito fundamental à moradia. Esse grave problema social e suas consequências notabilizaram-se na atual situação de pandemia da Covid-19, uma vez que nesses aglomerados se verificam as maiores incidências de casos e de vítimas fatais. Neste trabalho, procurou-se demonstrar que o destaque dado pela Constituição brasileira aos direitos sociais em 
geral e ao direito à moradia em especial impõe a todos os poderes do Estado uma atuação constante direcionada à concretização dos direitos sociais.

Ao atribuir status constitucional aos direitos sociais e proclamar o princípio da dignidade humana, a garantia dos direitos fundamentais sociais, na dimensão asseguradora do mínimo existencial, converte-se em dever que irradia por todas as funções estatais, independentemente do grau de normatividade que esses direitos alcancem no âmbito da Constituição.

Pela perspectiva do princípio da máxima eficácia e efetividade dos direitos fundamentais, os aspectos definidores da reserva do possível estão estreitamente vinculados aos princípios e objetivos constitucionais. Logo, reclamam o planejamento adequado e equitativo das despesas e ações estatais, de modo a garantir-lhe a maior efetividade possível. Para isso, faz-se necessário adotar critérios objetivos definidores das políticas públicas compatíveis com a garantia das prestações em curto, longo e médio prazos, de maneira que essas consubstanciem-se em políticas públicas de estado, que sobrevivam à alternância dos governantes e se perenizem independentemente da coloração política ideológica que esses venham a assumir.

No presente estudo defendeu-se igualmente que cabe ao Judiciário restabelecer a vontade da Constituição em caso de omissão do poder público em adotar as políticas públicas suficientemente necessárias para que todos tenham garantido o acesso ao núcleo mínimo do direito fundamental à moradia. Para isso, o Judiciário precisaria assumir um papel mais ativo na sua função controladora das decisões governamentais, não apenas à miúde em face do caso concreto como tem feito, mas também no âmbito macro de controle das políticas públicas destoantes da vontade constitucional, intentando e legitimando assegurar a todos os direitos sociais indispensáveis à manutenção da vida e da preservação da dignidade humana.

Com suporte na disciplina constitucional do direito fundamental à moradia e os princípios do estado democrático de direito, no qual se consubstancia o Estado brasileiro, entende-se que a reserva do possível é mitigada diante da intangibilidade do direito à moradia adequada na dimensão do mínimo vital. Concluiu-se, pois, pela inconstitucionalidade dos instrumentos de despesa pública que deixem de aportar recursos em volume razoável, aferido com base em comparação feita com a previsão geral dos gastos públicos igualmente essenciais, para a consecução do fim de se garantir a fruição do direito fundamental à moradia.

\section{Referências}

ALEXY, Robert. Teoria dos Direitos Fundamentais. Trad. de Virgílio Afonso da Silva. São Paulo. Malheiros: 2008. 
BARROSO, L.R. Curso de Direito Constitucional Contemporâneo os Conceitos Fundamentais e a Construção do Novo Modelo. 8a ed. São Paulo: Saraiva, 2019.

BRANCO, Paulo Gustavo Gonet. Ordenamento Jurídico, Constituição e Norma Fundamental. in Gilmar Ferreira Mendes, Inocêncio Mártires Coelho e Paulo Gustavo Gonet Branco. Curso de Direito Constitucional. São Paulo: Saraiva, 2009, p. 265-328.

BRASIL. Constituição (1988). Constituição da República Federativa do Brasil: promulgada em 5 de outubro de 1998: atualizada até a Emenda Constitucional no 20, de 15-12-1998. São Paulo: Saraiva, 2009.

BRASIL. IBGE, 2020. Aglomerados subnormais 2019. Disponível em: https://socecodem-ibgedgc.hub.arcgis.com/app/ac337eeee5164c0daa9c99f8689ad3f8. Acesso em: 13 jun. 2020.

BRASIL. Ministério da Saúde. Corona vírus Brasil. Disponível em: https://covid.saude.gov.br/. Acesso em: 27 jun. 2020.

CANOTILHO, JJ Gomes. Direito Constitucional e Teoria da Constituição. $6^{a}$ ed. Coimbra, Almedina: 2002.

KRELL, Andreas Joaquim. Realização dos direitos fundamentais sociais mediante controle judicial da prestação dos serviços públicos básicos: (uma visão comparativa. In Revista de Informação Legislativa. Brasília, v. 36 n. 144 out./dez. 1999, p. 239-260. Disponível em: https://www2.senado.leg.br/bdsf/handle/id/22/browse?type $=$ author\&value $=$ Krell\%2C + Andre as+Joachim. Acesso em: 20 jun. 2020.

MORAES, Alexandre. Direitos Humanos Fundamentais. São Paulo: Atlas, 2002.

NASCIMENTO, D. M.; BRAGA, R. C. Q. Déficit habitacional: um problema a ser resolvido ou uma lição a ser aprendida? Risco - Revista de Pesquisa em Arquitetura e Urbanismo, 9 (1) 2009, p. 98-109. Disponível em: https://repositorio.ufmg.br/bitstream/1843/AMSA94QGCL/1/mara_cristina_nogueira_teixeira_2012.pdf. Acesso em: 20 jun. 2020.

NETO, Claudio Pereira de Souza. Fundamentação e Normatividade dos Direitos Fundamentais: Uma Reconstrução Teórica à Luz do Princípio democrático. In Luís Roberto Barroso (org). A Nova Interpretação Constitucional: ponderação, direitos fundamentais e relações privadas. BARROSO, Luís Roberto (org). Rio de Janeiro: Renovar, 2008, p. 285-325.

RUSSO, Endyra de Oliveira. O conceito de déficit habitacional no Brasil: contexto de elaboração sob a ótica do sistema simbólico. v. 16 n. 1 (2015): Anais do XVI ENANPUR. Disponível em: http://anais.anpur.org.br/index.php/anaisenanpur/article/view/1635/1614. Acesso em: 23 jun. 2020.

SARLET, Ingor Wolfgang. A Eficácia dos Direitos Fundamentais. Porto Alegre: Livraria do Advogado, 2007.

SILVA, José Afonso. Curso de Direito Constitucional Positivo. São Paulo: Malheiros, 2000. 
SILVA, Luana Lima Bittencourt; GOMES, Almiralva Ferraz. Política pública de habitação e desenvolvimento socioeconômico: contribuição dos programas implantados em Belo Campo (BA). Revista Brasileira de Administração Política, v. 9, n. 1 (2016), p. 133-155. Disponível em: https://portalseer.ufba.br/index.php/rebap/article/view/22411/14374. Acesso em: 24 jun. 2020.

SOUZA, Sergio Iglesias Nunes. Direito à Moradia e de Habitação: Análise comparativa e suas implicações teóricas e práticas com os direitos da personalidade. São Paulo: Revista dos Tribunais, 2004.

STRECK, Lenio Luiz. O Papel da Jurisdição Constitucional na Realização dos Direitos Sociais Fundamentais. In: SARLET. Ingor Wolfgan (org.). Direitos Fundamentais Sociais: estudos de direito constitucional, internacional e comparado. Rio de Janeiro, Renovar: 2003, p. 169-261.

VASCONCELOS, José.; CÂNDIDO JR, José O. O Problema Habitacional no Brasil: Déficit, Financiamento e Perspectivas. Brasília: IPEA, Ab. 1996 (Texto para Discussão, 410). Disponível em: https://www.ipea.gov.br/portal/images/stories/PDFs/TDs/td_0410.pdf. Acesso em: 23 jun. 2020. 